\title{
关于绿色建筑和建筑节能设计的探讨
}

郝兵

齐齐哈尔市房屋征收办公室

DOI:10.18686/bd.v1i11.1090

[摘 要] 绿色建筑是指在建筑的全寿命周期内,最大限度地节约资源(节能、节地、节水、节材)、保护环境和减少污染, 为人 们提供健康、适用和高效的使用空间,与自然和谐共生的建筑。

[关键词] 绿色建筑; 建筑节能; 节能; 设计

我国的经济和社会正保持着高速发展的态势, 处于工 业化和城镇化快速发展阶段,工业的增长、居民消费结构的 升级,特别是城镇化进程的快速发展, 对能源、经济资源的需 求将更加迫切。这样,我们不得不正视我国能源(特别是不可 再生能源)、土地、水、原材料等资源严重短缺而实际利用效

时的传递,甚至会造成信息的丢失,而信息化的交流方式,改 变书信传递消息的弊端,为人们的交流。

\section{5 计算机发展趋势的预测}

计算机的进一步发展主要依赖于计算机技术的进一步 发展,随着我国市场需求的不断提升,对计算机技术水平的 要求也不断提升, 在这样的情况下进一步发挥人才的优势, 提高自主创新能力, 在现有技术的基础上进行进一步的创 新,从而促进新兴技术的进一步应用。

5.1 光计算机

光计算机是计算机未来发展的主要趋势, 其具有以下 几个优点:

首先, 光器件允许高光频率的大范围通过, 也就意味着 具有很大的库存带宽以及较大的传输处理的信息量。如果 出现两束出现干涉的光, 两束光之间就必须要具有相同的 频率以及相同的初始位相差和振动方向。所以,大量的波长 不同、波长相同振动方向不同的光波可以同时在同一根光 导纤维中行进,而且它们当中不会出现相互干涉的情况。

其次, 光计算机信息传输的过程中具有很小的会发生 畸变和失真的概率, 而且具有很快的运算速度。在介质中光 与电都有极快的传播速度,但两者还是存在一些差异。光计 算机就是所谓的 “ $F$ 我” 导线计算机,在光介质中光可以实 现无寄生电感、电容、电阻等问题的快速传播,并且没有接 地电位差。这就使信息畸变和信息失真在传输过程中大大 降低, 相对于电子器件而言, 光器件的开关速度非常之快。

5.2 量子计算机

量子计算机在平行运算处理方面具有很大的优势。例 如,将一份遗失文件从一个非常大的办公楼当中找出来。要 是对传统计算机的寻找方式予以利用就必须对每个办公室 进行逐一查询, 而量子计算机就可以以寻找者提出的条件 和要求为根据, 方便快捷的将与被寻找文件最为相似的副
率低、环境污染严重且仍在不断加剧的事实。因此中国要走 可持续发展道路,发展绿色建筑与节能建筑是刻不容缓的。

\section{1 建筑能耗的基本内容}

1.1 什么是建筑能耗

建筑能耗的定义: 民用建筑在运行中所产生的能耗, 即
本复制出来,同时进人所有办公室同时搜索。

\section{3 化学计算机}

化学计算机的运行机理是以一种名为微观碳分子的化 学制品为信息载体,以实现信息的储存于传输。因此,其体积 更小、运算速度更快、计算机能力更大,在信息传输速度的 方面甚至可能超过人脑, 因此发展前景巨大。如何取代硅电 子部件来研究碳基制品是化学计算机发展的关键所在。虽 然这一领域现今还处于探索阶段, 但也已取得了不少进展, 前景可观。

\section{4 生物计算机}

所谓的生物计算机是指具有生物活性, 能够与人体组 织进行结合的计算机, 其尤其可以与人类的大脑和神经系 统进行联系。如此以来,大脑就可以直接指挥生物计算机,使 其成为大脑的一个辅助或扩充装置, 并由人体的细胞来为 其补充能量,无需外界的能源补充。生物计算机将成为人类 学习、思考和创造的帮手,并且能耗极小。

\section{6 结束语}

综上所述, 计算机如今已经完全融人到人们的日常生 活和工作中,并且正在发挥着越来越重要的作用,并且科学 技术的不断更新和完善, 也会使得计算机技术持续发展, 如 今经济全球化的趋势也越来越明显, 我国各个领域也在不 断加快与国际接轨的步伐。

\section{参考文献:}

[1] 梁文宇. 计算机应用的现状与计算机的发展趋势 [J].科技经济市场,2017,(02):188-190.

[2] 刘青梅. 计算机应用的现状与计算机的发展趋势 [J].电脑知识与技术, 2016,12(25): 193-194.

[3]李洋.计算机应用的发展现状和发展趋势[J].科技 传播,2016,8(17):107-108. 
在住宅、办公建筑、学校、商场、宾馆、交通枢纽、文体娱乐设 施等非工业建筑内为居住者或使用者提供的采暖、空调、通 风、照明、炊事、生活热水及其他为建筑服务功能所使用的 能源。我国的建筑用能主要分为以下几类:

(1)北方城镇采暖用能。是指采取集中供热方式的省、自 治区和直辖市在采暖季所消耗的包括各种形式的集中采暖 和分散采暖的建筑用能。(2)除采暖用能外的城镇住宅用能。 指的是除北方地区采暖能耗外的城镇住宅用能, 其中包括 日常生活中电气、照明、炊事、空调、生活热水和除北方地区 以外的各地区的冬季采暖用能。(3)除严寒和寒冷地区采暖 能耗以外的商业及公共建筑用能。指的是除严寒和寒冷地 区的采暖能耗外的商业及公共建筑内由于各类活动所产生 的建筑能耗。其中包括各类服务设施、电梯、照明、空调、插 座和其他地区的冬季采暖能耗。(4)农村住宅用能。是指农村 家庭生活在采暖、照明、炊事、热水、家用电器等方面消耗的 能源。该类建筑主要使用电力、煤炭以及生活质能作为建筑 用能。

\section{2 全球建筑能耗近况}

作为全球用能的主要部分之一, 建筑用能在发达国家 所占的比例远远大于普通发展中国家, 产生这一现象的主 要原因是发达国家具有较强的经济实力, 对生活水平的要 求也比较高,有足够的能力为其使用的建筑能源买单。以美 国为例, 该国在近年来所消耗的能源占全球能源的 $1 / 5$ 之 多, 而其在建筑的运营阶段所消耗的能源数量占全球的近 $1 / 10$ 。

\section{3 中国建筑能耗近况}

我国目前城镇居民建筑运行耗电量占全国总发电量的 $22 \% \sim 24 \%$, 北方地区城镇供暖的燃煤量占我国非发电用煤 量的 15\% 18\%。建筑消耗的能源占全国商品能源的 $21 \%$ $\sim 24 \%$ 。而这些数值都仅为建筑运行所消耗的能源, 不包括 建筑材料制造用能及建筑施工过程能耗。

\section{2 绿色建筑节能设计方法}

2.1 建筑的选址、布局的节能设计

合理的建筑布局能够最大化场地和资源的利用效率, 从而能够改善建筑物的室内环境, 减少建筑物热排放,优化 建筑物布局的主要措施为: 第一, 规划好建筑内内部的功能 区分,建筑物北面尽量安排不需设置窗户的功能区, 将功能 相似的区域尽量布置在同一地区，这样能够方便建筑物内 部空调和通风系统的设计。第二,为减少建筑物的资源能源 消耗,应尽量利用已有的地形当做其围护结构。第三,按照当 地的主要风险和纬度,优化建筑物朝向,尽量利用当地的风 能和太阳能等资源,同时最大化使用当地的其他自然资源。 第四, 利用当地已有的各种植物来减小建筑物的热负荷影 响。

2.2 建筑体型、朝向、配套设施的节能设计

2.2.1 建筑体型的设计

建筑空间系统和建筑物形体不仅仅是绿色节能建筑的
重要组成部分,也是地域性建筑本质特征的表现。建筑物的 室内热能耗与其形体之间有着极为紧密的联系, 而建筑物 的热能也是其重要的衡量指标。建筑物本身的形体系数越 小,说明建筑物形态较为规整, 能够极大地减少夏季制冷和 冬季供暖所产生的热工损耗,反之则较易于利用自然通风。 正确把握建筑物自身的形体系数也是节能建筑的重要设计 因素。在建筑物本身的设计中,可以适当使用别墅理念。借 鉴别墅中线角、阳台、门窗、屋顶和建筑饰面激励的丰富性, 及其与自然相结合的特点, 这样能够体现出自然与人类和 谐发展的基本原则, 从绿色环保理念出发能够使建筑实现 可持续发展。

\subsection{2 建筑朝向的设计}

建筑物的朝向对于建筑节能有很大的影响。当建筑物 为南北朝向时,耗能较少。近年来, 设计实践中的一种现象是 越来越多的出现偏轴方位的建筑朝向,这种做法, 可在活跃 建筑群体、节约用地、处理建筑外形等方面带来一些益处, 但从长远角度看, 我们还是要强调正南朝向(包括南偏东、偏 西 $15^{\circ}$ 以内朝向)的节能意义。因此, 从节能的角度出发, 如 总平面布置允许自由考虑建筑物的形状和朝向, 则应首先 选长方形体型, 朝向尽可能大体朝南,避免东西向。在确定朝 向时, 另一个必须注意的问题是要处理好建筑朝向与季风 风向的关系。在北方寒冷地区,主要使用房间的朝向应尽可 能避免对着冬季主导风向,在南方炎热地区,建筑的朝向宜 与夏季主导风向人射角保持在 $30^{\circ}-60^{\circ}$ 的范围内。

建筑节能的方式主要包括两个方面:(1) 主动式节能方 式。指的是在建筑的运营阶段由于使用高效低能的建筑设 备和建筑电气而减少的建筑用能。(2)被动式节能方式。是指 减少甚至取消建筑设备和建筑电气, 采用非设备化的方式 减少建筑用能。这种节能方式是通过直接利用现有的气候 和环境, 即风力、太阳能、环境温湿度、植被、场地地形等条 件与建筑设计融合来减少与外界的热交换, 从而达到降低 建筑能耗的目的。

\section{2 .3 建筑物和配套设施的设计}

建筑物配套设施的设计能够保证建筑物的健康性和室 内环境舒适, 在设计建筑物配套系统时,除了使用各种高效 环保的建筑材料之外,还有以下几项措施:第一,新风系统的 设计。新风系统是改善建筑物室内环境质量的重点,同时能 够极大地提高室内的空气质量。无论夏季还是冬季,室内与 室外之间都会存在较大的温差, 而新风量越大也就说明处 理新风会消耗更多的资源能源。第二,自然资源的使用。节 约能源是绿色建筑的本质特点之一, 绿色节能建筑的平均 能耗量是同类建筑的一半左右, 在节能的同时还要保证室 内环境的质量水平,所以说, 自然能源的使用在一定程度上 决定着建筑能否实现绿色节能。建筑物常用的自然能源主 要包括太阳能、地热能和风能等几种。第三,实现自然通风。 建筑物自然通风是指通过大气自身的热压作用实现通风的 一种方式, 这种方式的主要标志是没有任何的能源消耗,便 


\section{路基基层水泥稳定碎石横向裂缝防治措施探讨}

安平 刘卓雨

日照交通发展集团有限公司

DOI: 10.18686/bd.v1i11.1102

[摘 要] 水泥稳定碎石路基基层被广泛应用在各级公路建设中, 其质量直接关系到面层的施工质量,如施工或设计不当, 极 易造成面层出现反射裂缝等各类病害。而横向裂缝是水泥稳定碎石基层最常见的病害之一, 对其的预防与处治显得尤为重 要。基于此,结合某公路工程,对路基基层水泥稳定碎石横向裂缝的成因及其防治进行了探讨分析。

[关键词] 水泥稳定碎石; 路基基层;横向裂缝;成因;处理;防治;措施

水泥稳定碎石路基基层属于半刚性基层由于兼具刚性 基层与柔性基层的优点, 是目前我国公路工程应用最广泛 的基层结构形式。半刚性基层结构稳定、水稳性好、耐久,在 荷载的作用下允许有一定的变形, 且强度随着时间而不断 增长。但水泥稳定碎石基层在使用过程中,由于种种原因出 现开裂,尤其以横向裂缝最为严重。以下就路基基层水泥稳 定碎石横向裂缝防治措施进行探讨。

\section{1 某公路工程概况}

某公路工程设计速度为 $60 \mathrm{~km} / \mathrm{h}$, 属于二级公路,路线全 长 $2.490 \mathrm{~km}$, 路基全宽 $10.0 \mathrm{~m}$, 其中路面宽 $9.5 \mathrm{~m}$, 两侧各设 $0.25 \mathrm{~m}$ 的路缘石。路面面层结构采用沥青混凝土,下面层采 用 $4 \mathrm{~cm}$ 中粒式沥青混凝土,上面层采用 $3 \mathrm{~cm}$ 细粒式沥青混 凝土; 基层采用 $20 \mathrm{~cm}$ 水泥稳定碎石基层。路面基层采用水 泥稳定碎石基层,设计水泥剂量为 5\%,采用 425 普通硅酸 盐水泥。施工过程中,水稳基层出现横向裂㖓。出现裂缝地 段属于湿软地基。

\section{2 路基基层水泥稳定碎石横向裂缝的成因分析}

公路工程中的水泥稳定碎石路基基层属于半刚性基 层,而缩裂是半刚性基层最顽固的病害形式之一,其原因有 很多种,笔者认为主要包括:(1)原材料原因。主要是原材料自 身质量不合格,如骨料粒径、形状不符合要求, 石粉含泥量过

可以实现改善室内空气和整体环境质量的目的, 这种方式 所达到的效果不亚于空调的作用。但是,自然通风会在一定 程度上受到建筑物结构和当地自然条件的限制, 所以,为了 达到良好的通风效果, 实现预期目标, 还要适当配合以其他 自动调控设备。

\section{3 结语}

进行建筑节能设计时,有两个基本特征需要特别注意: 一个是考虑地区性差异, 另一个是注重过程控制。前者是指 由于不同地理、气候环境下,建筑使用者的生活习惯各有不 同,对建筑形式的要求也有相应的差别, 因此,对建筑节能技 术的需求也会存在一定的差距; 后者指的是即使是同一环 境、同一地域下,建筑也会因为不同季节、不同月份、不同时 刻而存在不同的温度、湿度、太阳辐射、光照度以及风环境,
高,水泥存放时间过长或水泥剂量不足等。考虑到拌和、运 输、推铺与碾压过程中的损失, 水泥剂量应比设计剂量大 $0.5 \%$ - $1 \%$, 水泥剂量过小会使水泥水化之后的产物减少, 直接降低强度,引起开裂。水泥剂量过大也会造成水泥水化 产物增多,基层结构体积膨胀,引起开裂。(2)施工原因。第一、 水泥稳碎石路基基层材料拌制过程中控制不到位造成的配 合比不准确,含水率不足等。配合比不准确直接影响到基层 材料的总体质量, 而含水率的大小对压实度的影响很大。通 常认为在最佳含水率的情况下压实, 容易达到最大的密实 度,得到最大干密度,进而达到最大压实度。第二、水泥稳碎 石路基基层材料在运输过程中没有按要求加盖篷布, 运输 时间过长, 造成水泥超过终凝时间等。按规定, 从运输到压实 完成时间不得超过 3 - $4 \mathrm{~h}$, 否则水泥达到终凝时间, 材料将 失去原有的使用性能。第三、碾压不足,造成压实度达不到 设计要求,进而影响强度。实践证明, 压实度越高,产生缩裂 的程度越小。第四、养生不到位。未按要求进行洒水覆盖养 生,养生期应控制在 7d 以上。如果酒水不足,极易出现干缩 裂缝,并影响水泥水化,使基层强度降低。

\section{3 某公路工程中的路基基层水泥稳定碎石横向裂缝处} 理分析

某公路工程中的路基基层出现横向裂缝的部位是典型

即使在相类似的时刻环境下, 不同类型的使用者对建筑的 需求也不尽相同,因此,在不同时刻,建筑的能耗也会产生不 同的变化, 在进行建筑节能设计时, 要适当的调整建筑设计, 使其按照人们的需求而进行控制。

\section{参考文献:}

[1]清华大学建筑节能研究中心.中国建筑节能年度发 展研究报告 2012 [M]. 北京: 中国建筑工业出版社,2012: $2-4,11$.

[2]任海滨.刍议现代建筑的绿色节能设计[J].山西建 筑,2013,39(2):201-202.

[3]杨志鹏.我国绿色建筑与建筑节能技术应用研究进 展[J].中国建材科技,2017,26(01):9+14. 